\title{
Characterisation of organic contaminants in the CLOUD chamber at CERN
}

\author{
R. Schnitzhofer ${ }^{1}$, A. Metzger ${ }^{2}$, M. Breitenlechner ${ }^{1}$, W. Jud ${ }^{1}$, M. Heinritzi ${ }^{1}$, L.-P. De Menezes $^{3}$, J. Duplissy ${ }^{3,5}$, \\ R. Guida ${ }^{3}$, S. Haider ${ }^{3}$, J. Kirkby ${ }^{3}$, S. Mathot ${ }^{3}$, P. Minginette ${ }^{3}$, A. Onnela ${ }^{3}$, H. Walther ${ }^{4}$, A. Wasem ${ }^{3}$, A. Hansel ${ }^{1,2}$, and \\ the CLOUD Team ${ }^{3}$ \\ ${ }^{1}$ Institute of Ion Physics and Applied Physics, University of Innsbruck, Innsbruck, Austria \\ ${ }^{2}$ Ionicon Analytik, Innsbruck, Austria \\ ${ }^{3}$ CERN, Geneva, Switzerland \\ ${ }^{4}$ Paul Scherrer Institute, Villigen, Switzerland \\ ${ }^{5}$ Department of Physics, University of Helsinki, P.O. Box 64, 00014 Helsinki, Finland
}

Correspondence to: A. Hansel (armin.hansel@uibk.ac.at)

Received: 28 June 2013 - Published in Atmos. Meas. Tech. Discuss.: 22 August 2013

Revised: 6 December 2013 - Accepted: 9 December 2013 - Published: 18 July 2014

\begin{abstract}
The CLOUD experiment (Cosmics Leaving OUtdoor Droplets) investigates the nucleation of new particles and how this process is influenced by galactic cosmic rays in an electropolished, stainless-steel environmental chamber at CERN (European Organization for Nuclear Research). Since volatile organic compounds (VOCs) can act as precursor gases for nucleation and growth of particles, great efforts have been made to keep their unwanted background levels as low as possible and to quantify them. In order to be able to measure a great set of VOCs simultaneously in the low parts per trillion (pptv) range, proton-transferreaction mass spectrometry (PTR-MS) was used. Initially the total VOC background concentration strongly correlated with ozone in the chamber and ranged from 0.1 to 7 parts per billion (ppbv). Plastic used as sealing material in the ozone generator was found to be a major VOC source. Especially oxygen-containing VOCs were generated together with ozone. These parts were replaced by stainless steel after CLOUD3, which strongly reduced the total VOC background. An additional ozone-induced VOC source is surfaceassisted reactions at the electropolished stainless steel walls. The change in relative humidity $(\mathrm{RH})$ from very dry to humid conditions increases background VOCs released from the chamber walls. This effect is especially pronounced when the $\mathrm{RH}$ is increased for the first time in a campaign. Also the dead volume of inlet tubes for trace gases that were not continuously flushed was found to be a short but strong
\end{abstract}

VOC contamination source. For lower ozone levels (below $100 \mathrm{ppbv}$ ) the total VOC contamination was usually below $1 \mathrm{ppbv}$ and therewith considerably cleaner than a comparable Teflon chamber. On average about $75 \%$ of the total VOCs come from only five exact masses (tentatively assigned as formaldehyde, acetaldehyde, acetone, formic acid, and acetic acid), which have a rather high vapour pressure and are therefore not important for nucleation and growth of particles.

\section{Introduction}

According to the IPCC 2007 report (Solomon et al., 2007), aerosols and clouds represent the largest uncertainties in global climate models, and their estimated significant influence on the observed global warming remains poorly understood. The aim of the initial CLOUD (Cosmics Leaving OUtdoor Droplets) experiments at CERN (European Organization for Nuclear Research) is to thoroughly investigate the first crucial steps of cloud formation, i.e. the nucleation of condensable vapours and how galactic cosmic rays (GCRs) may enhance this process by ion-induced nucleation (Carslaw et al., 2002). The first results from CLOUD (Kirkby et al., 2011) showed that the enhancement due to ions and ammonia was insufficient to account for the nucleation of sulfuric acid particles in the lower atmosphere, indicating that organic ternary vapours are required. Organic trace 
vapours initiate the nucleation process together with sulfuric acid and are fundamentally involved in the subsequent growth of the initial cluster to gain the crucial size when water starts to condense and cloud droplets form (Metzger et al., 2010; Kulmala et al., 2013).

In the CLOUD experiments great efforts have been made to control the chamber conditions, including the introduced gases. Since organic vapours are expected to impact nucleation and growth of particles, their background levels need to be kept small. Despite a considerable number of similar experiments in various environmental chambers around the world, reports about background organic contamination are rare. Wisthaler et al. (2008) report an increase of formaldehyde and other $\mathrm{C}_{2}$ to $\mathrm{C}_{10}$ aldehydes when ozone is inserted into the Teflon SAPHIR chamber (Jülich, Germany). Total organic contaminations are given for the Teflon chambers EUPHORE $<0.3 \mu \mathrm{g} \mathrm{m}^{-3}$ (Bloss et al., 2005), PSI 4 parts per billion (ppbv) (Paulsen et al., 2005), and Caltech Indoor Chamber Facility below limit of detection (Cocker et al., 2001).

In order to be able to measure a large set of different organic compounds, the proton-transfer-reaction (PTR) technique has been chosen to monitor the background concentration of organics in the chamber. The aim of CLOUD was to study first the effect of GCRs on binary sulfuric acid water nucleation and subsequently to investigate more complex systems such as the ternary sulfuric acid-ammoniawater system (Kirkby et al., 2011). Later on the impact of amines (dimethylamine, DMA) and organic compounds (pinanediol, PD) on new particle formation and growth was studied (Almeida et al., 2013, Schobesberger et al., 2013, Keskinen et al., 2012). The first CLOUD chamber experiment (CLOUD1) was conducted during NovemberDecember 2009. So far eight campaigns have been carried out: each one lasted between 1 and 3 months. Here we present data from CLOUD1-3 and CLOUD7-8.

\section{Experimental}

\subsection{The CLOUD chamber}

A $26 \mathrm{~m}^{3}$ electropolished stainless-steel cylinder is the central part of the CLOUD experiment. It can be temperaturecontrolled over the whole range of atmosphere-relevant temperatures $\left(-65^{\circ} \mathrm{C}\right.$ to $\left.100^{\circ} \mathrm{C}\right)$, with an accuracy of $0.1^{\circ} \mathrm{C}$. The chamber can be evacuated from 1200 to $1000 \mathrm{hPa}$ over any chosen time interval above $10 \mathrm{~s}$, in order to simulate the adiabatic cooling in ascending air masses and form clouds. In addition, an adjustable $\pi^{+}$beam from the CERN Proton Synchrotron can simulate cosmic rays (for details see Duplissy et al., 2010, and Kirkby et al., 2011). A schematic drawing of the CLOUD chamber is shown in Fig. 1.
A crucial part of the chamber is the gas supply system. The CLOUD atmosphere consists of $79 \%$ nitrogen $\left(\mathrm{N}_{2}\right)$ and $21 \%$ oxygen $\left(\mathrm{O}_{2}\right)$, and a varying amount of trace gases like water vapour, ozone $\left(\mathrm{O}_{3}, 0-1000 \mathrm{ppbv}\right)$, sulfur dioxide $\left(\mathrm{SO}_{2}, 0-60 \mathrm{ppbv}\right)$, ammonia $\left(\mathrm{NH}_{3},<0.35\right.$ pptv2 ppbv; Bianchi et al., 2012), pinanediol (PD, $\mathrm{C}_{10} \mathrm{H}_{18} \mathrm{O}_{2}, \mathrm{O}_{-}$ 21 ppbv; Schobesberger et al., 2013), dimethylamine (DMA, 0-100 pptv, $\mathrm{C}_{2} \mathrm{H}_{7} \mathrm{~N}$; Praplan et al., 2012; Almeida et al., $2013)$, and $\alpha$-pinene $\left(\mathrm{C}_{10} \mathrm{H}_{16}, 0-1600 \mathrm{pptv}\right)$. All these gases and their injection into the chamber pose potential sources of organic impurities and are therefore treated with particular care. Synthetic air is provided by evaporation from cryogenic liquid $\mathrm{N}_{2}$ and $\mathrm{O}_{2}$, mixed in the gas phase in ratio $79: 21$. A continuous flow into the chamber of 100-160 standard litre per minute (slpm) of humidified synthetic air mixed with trace gases compensates for air extracted by the analysing instruments.

Water vapour concentration can be controlled over 6 orders of magnitude with a deviation of $1 \%$ relative humidity $(\mathrm{RH})$. Water is purified by circulation through a bank of Millipore Super-Q filters (MQ water), de-ionised and added to the $\mathrm{N}_{2}-\mathrm{O}_{2}$ gas stream via a Nafion humidifier.

One of the essential gases for nucleation is sulfuric acid. In the CLOUD chamber it is produced by photo-dissociation of ozone in the presence of $\mathrm{SO}_{2}$, water vapour, $\mathrm{O}_{2}$ and $\mathrm{N}_{2}$. To avoid heat load from the light source, a fibre optic system is installed that produces an uniform illumination (240$750 \mathrm{~nm}$ ) in the chamber and therefore a uniform sulfuric acid production. The temperature increase in the chamber is smaller than $0.005^{\circ} \mathrm{C}$ at full illumination (Kupc et al., 2011).

The trace gases are supplied in concentrated form and then highly diluted with synthetic air to ensure minimum contamination from the supply.

Ozone is generated by a low-pressure mercury lamp (CLOUD1-CLOUD3). The plastic sealing of this device was suspicious as a potential source of organic impurities during exposure of very high ozone levels. Therefore it was replaced by a CERN designed and built all stainless steel and quartz ozone generator from CLOUD4 on.

The gases are injected at the bottom of the chamber close to one of the two mixing fans in order to distribute them quickly and uniformly throughout the whole chamber. This is important to reach newly adjusted levels of trace gases rapidly (Voigtlaeander et al., 2012).

There are 16 ports installed in the mid-plane of the chamber, to which sampling probes are mounted. The inner tips of the sampling probes project into the chamber a distance of $50 \mathrm{~cm}$ (CLOUD1-3) or $35 \mathrm{~cm}$ (CLOUD4 and later). The pressure in the chamber is maintained at least $5 \mathrm{hPa}$ above ambient. Accidental low pressure in the chamber bears the danger of backflow through the various instruments to the chamber and contamination with for example butanol from the condensation particle counters (CPCs). Therefore an independent fail-safe system has been implemented to ensure 
the chamber pressure never falls below $5 \mathrm{hPa}$ above ambient pressure.

\subsection{PTR-MS}

To be able to monitor a great set of volatile organic compounds (VOCs) quantitatively in the low pptv range in real time and to identify the individual species, the PTR technique has been chosen. Proton-transfer-reaction mass spectrometry (PTR-MS; Hansel et al., 1995) is a chemical ionisation method for real-time measurements of VOCs. $\mathrm{H}_{3} \mathrm{O}^{+}$ ions, produced from pure water vapour in a glow discharge ion source, are injected into a drift tube which is continuously flushed with sampling air. $\mathrm{H}_{3} \mathrm{O}^{+}$ions transfer protons, at every collision, to compounds that have a higher proton affinity than water $\left(691 \mathrm{~kJ} \mathrm{~mol}^{-1}\right.$; i.e. most VOCs except alkanes). The protonated VOCs are then detected and quantitatively analysed by a quadrupole (CLOUD1) or a timeof-flight (ToF; CLOUD2, CLOUD3, CLOUD4, CLOUD7, and CLOUD8) mass spectrometer. In contrast to the PTRquadrupole system (PTR-Q-MS), the PTR-ToF-MS provides full mass scans within a fraction of a second. In addition, the high mass resolving power (about 5000 full width at half maximum (FWHM)), combined with the high mass accuracy (2.5 ppm), allows for unambiguous sum formula identification (Graus et al., 2010).

\subsection{Inlet system and background correction}

The inlet system has been especially designed in order to minimise inlet wall losses and ozone-induced surface reactions. A combination of high flow and heated inlet tubes should guide the VOCs most efficiently to the instruments. Figure 2 shows a schematic drawing of the whole PTR-MS inlet system. A 3/8" OD (7 mm ID) Sulfinert coated stainless steel tube projects $50 \mathrm{~cm}$ (CLOUD1-3) to $35 \mathrm{~cm}$ (CLOUD4 and later) into the CLOUD chamber to draw the air sample into the PTR instruments. Through this tube, sample air is continuously drawn between 8 and $11 \mathrm{slpm}$ (resulting in a Reynolds number of 2300) depending on the temperature of the chamber air. After an additional $15 \mathrm{~cm}$ section of $3 / 8^{\prime \prime}$ stainless steel tube, a $1 / 16^{\prime \prime}$ Silcosteel capillary extracts about $1 \mathrm{slpm}$ sample air from its centre. From this point on, all surfaces which are in contact with the sample air are heated to $60^{\circ} \mathrm{C}$. The capillary (as short as possible; $25 \mathrm{~cm}$ ) has two more T-connections. One of them is used to introduce periodically purified air to perform instrumental background measurements and the other one to have a pressurecontrolled inlet. Finally, only $0.011 \mathrm{slpm}$ (CLOUD 1-3, 4) or $0.7 \mathrm{slpm}$ (CLOUD 7,8 ) enter the drift tube of the PTR instruments.

Measurements close to the limit of detection (LOD) require an accurate and continuous determination of the instrumental background. During the CLOUD campaigns, background measurements were usually performed 4-5 times per day with different durations ( $1 / 2 \mathrm{~h}$ to several hours). For these measurements 3 slpm of chamber air were purified using two Pd-Pt catalytic converters (EnviCat ${ }^{\circledR}$, VOC 5538, Süd-Chemie AG, Germany) arranged in series. The purified gas stream was injected into the $1 / 16^{\prime \prime}$ capillary. Then $1 \mathrm{slpm}$ of this air was pumped to the instrument, and the rest was displaced to the 3/8" tube and pumped away. The inlet system was slightly different at each CLOUD campaign. For example during CLOUD3 another PTR-MS, modified to measure ammonia, sampled chamber air in the same way from the same $3 / 8^{\prime \prime}$ stainless steel tube. During CLOUD7 the zero air flow to the T-connection was inadvertently set too low so the "zero air" contained $25 \%$ chamber air for the first 2 weeks of the campaign. However, these data could subsequently be corrected since all flows were recorded.

\subsection{Calibration}

The PTR instruments were calibrated about five times during each campaign, using gas standards (Apel-Riemer Inc., Denver, CO, USA). The gas standards contained a set of pure and oxygenated hydrocarbons, which were dynamically diluted into purified air and fed to the PTR instruments. Based on these calibrations, we estimated a total accuracy of the instruments of $<13 \%$ at $1 \mathrm{ppbv}$ for the compounds included in the gas standard. This is due to uncertainties given for the calibration gas and the dilution system $(5.2 \%)$ and the precision of the counting system of $12 \%$ (for acetone at $1 \mathrm{ppbv})$. Formaldehyde $(\mathrm{HCOH})$ also included in the gas standard shows a water-dependent sensitivity because its proton affinity is only slightly higher than that of water, and therefore there is a backward reaction (Hansel et al., 1997). The amount of the backward reaction depends on the ambient humidity, which adds to the water coming from the ion source (for details see Vlasenko et al. (2010). The relative distribution of the $\mathrm{H}_{3} \mathrm{O}^{+}$(mass to charge ratio $(\mathrm{m} / z) 19$ ) and $\mathrm{H}_{2} \mathrm{O} \mathrm{H}_{3} \mathrm{O}^{+}(m / z$ 37) ions detected is also dependent on ambient humidity with a higher relative amount of $\mathrm{m} / z 37$ during humid conditions. Due to high amount of water ions, they can only be counted correctly at the natural isotopes $\mathrm{H}_{3}{ }^{18} \mathrm{O}^{+}$ $(m / z 21)$ and $\mathrm{H}_{2}{ }^{18} \mathrm{O} \mathrm{H}_{3} \mathrm{O}^{+}(m / z 39)$. Having various calibrations at constant instrument conditions (i.e. a constant water stream from the ion source into the drift tube, a constant drift tube temperature, and a constant $E / N$ in the drift tube) and at different ambient humidities (see Fig. 3), we can give a humidity-dependent sensitivity of

$\varepsilon_{(\mathrm{HCOH})}=105 \cdot \operatorname{ncps}_{(m / z 39)}-0.7$

using $\mathrm{H}_{2}{ }^{18} \mathrm{O} \mathrm{H}_{3} \mathrm{O}^{+}(\mathrm{m} / z$ 39) as a reference for humidity of the air sample. Similar water-dependent formaldehyde sensitivities were found during laboratory calibrations and inflight calibrations by Warneke et al. (2011). 


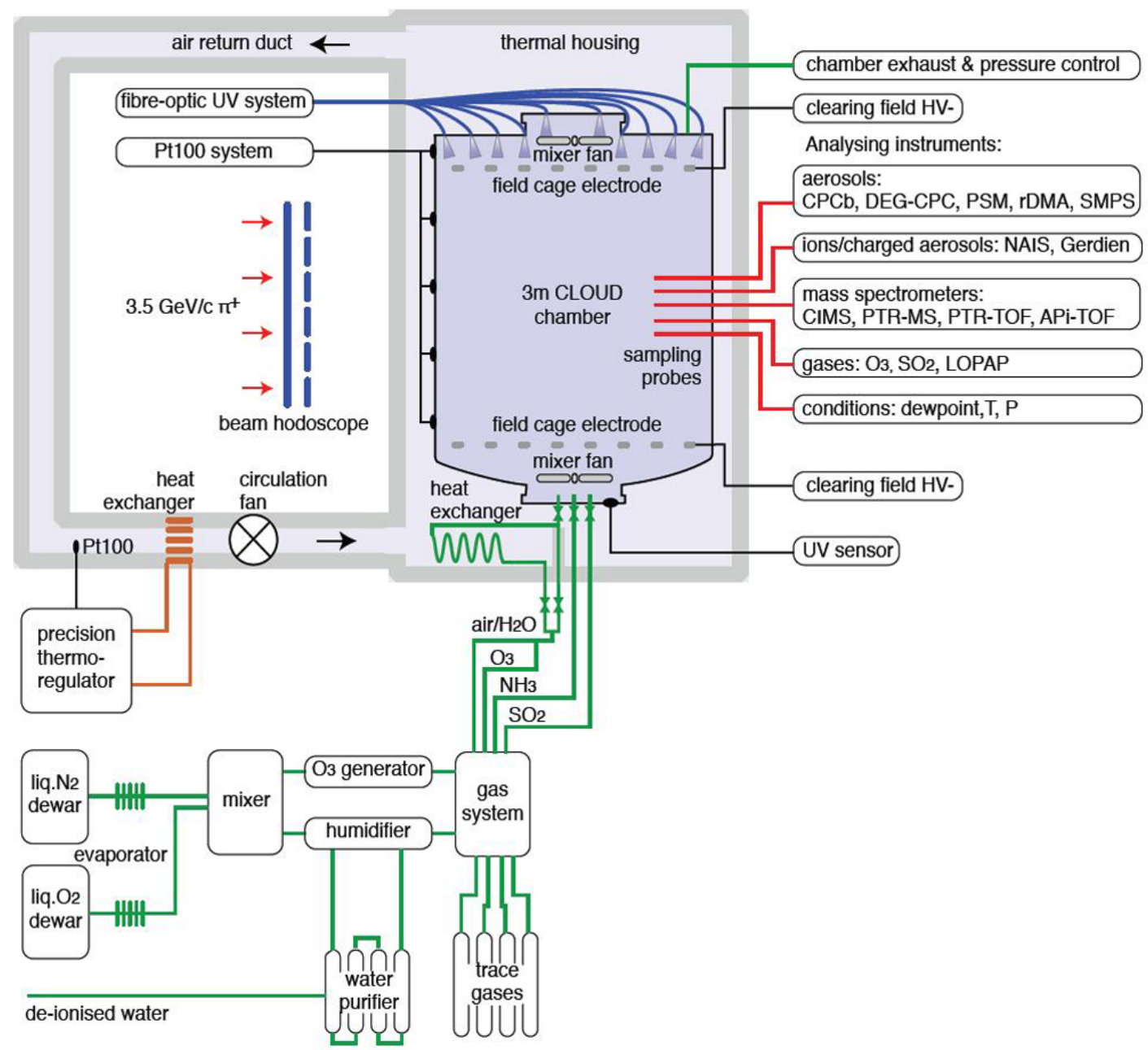

Figure 1. Schematic drawing of the CLOUD chamber, the gas system and the connected instruments (Kirkby et al., 2011).

Due to the lower overall sensitivity, the total accuracy for formaldehyde at $1 \mathrm{ppbv}$ is between $25 \%$ (dry) and $50 \%$ (humid).

For compounds that were not included in the gas standard, we used the sensitivity derived from calibrated oxygenated and pure hydrocarbons (compare Müller et al., 2012). The sensitivities could be cross-checked using the formula

$\varepsilon(R)=10^{-3} \frac{k L}{\mu_{0} N_{0}} \cdot \frac{N^{2}}{E} \cdot \frac{T\left(\mathrm{RH}^{+}\right)}{T\left(\mathrm{H}_{3} \mathrm{O}^{+}\right)}$

given by de Gouw et al. (2003) and reaction rate constants given by Cappellin et al. (2012). Here $R$ represents the individual VOCs, $k$ the reaction rate constant, $L$ the length of the drift tube, $\mu_{0}$ the reduced ion mobility, $N$ the gas number density, $N_{0}$ the gas number density at standard pressure and temperature, $E$ the electric field strength, and $T$ the transmission of the individual ions.

The LOD of the individual compounds is determined from the $2 \sigma$ uncertainty from the background measurements (compare Table 1).
Since PTR-ToF-MS provides sum formula identification, we could insert a oxygenated hydrocarbon sensitivity or a pure hydrocarbon sensitivity for every compound above the LOD not explicitly calibrated. Therefore, the overall amount of PTR-detectable VOCs (total VOCs) in the chamber can be calculated in parts per billion by volume (ppbv). Multiplying the individual compounds by their carbon atom number and adding up all compounds gives the total carbon mole fraction detected in the chamber (parts per billion by volume of carbon; ppbvC). When accounting for the uncertainty of the calibration and the counting system, the average mixing ratio of total VOCs can be given with an uncertainty of $40 \%$.

\section{Results}

The measurement principle of the PTR technique does not require sample preparation, and therefore data can be acquired in real time. Although these real-time data do not pass several quality checks, they can provide a first glance at the 


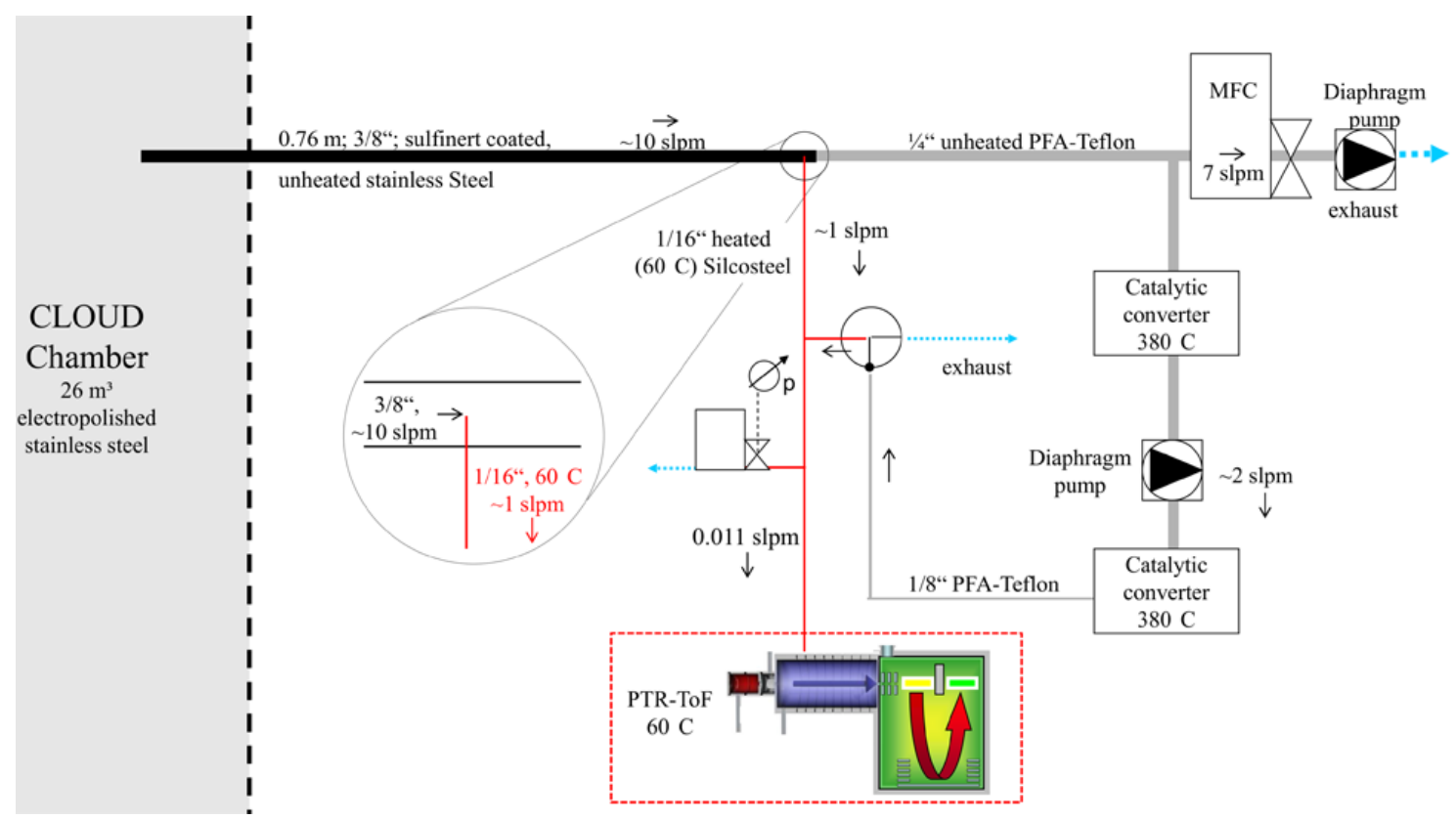

Figure 2. Schematic drawing of the PTR-Q-MS/PTR-ToF-MS inlet system during the various CLOUD campaigns.

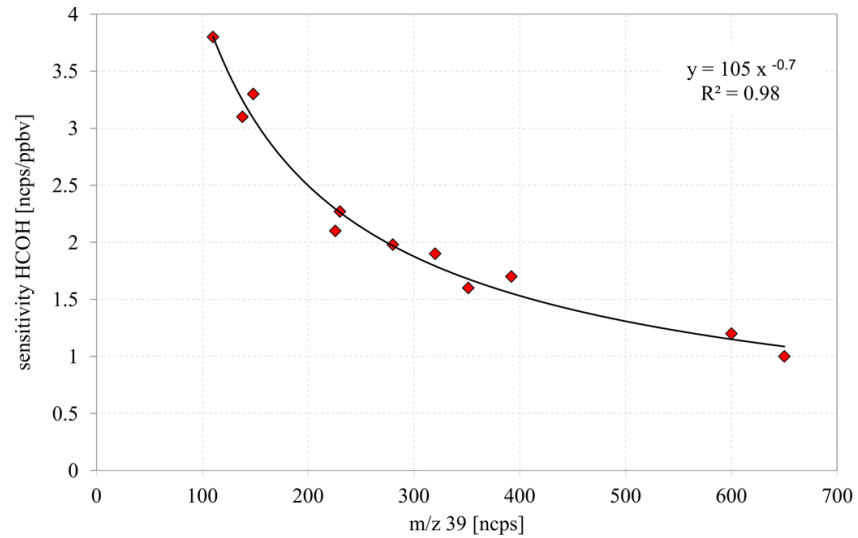

Figure 3. Scatter plot of formaldehyde sensitivities versus $\mathrm{H}_{2}{ }^{18} \mathrm{O}$ $\mathrm{H}_{3} \mathrm{O}^{+}(\mathrm{m} / z$ 39) as a reference for the absolute humidity in the drift tube.

experiment. During CLOUD these data provided a first estimation of the chamber cleanliness.

The inlet system was designed with particular care in order to keep the artificial loss or gain of VOCs on the inlet surfaces as low as possible. However, for some sticky compounds (particularly for acetic acid), the response time (switching between chamber measurements and zero calibration) was close to $1 \mathrm{~h}$. Consequently, zero calibrations had to be elongated until a constant level was reached, and data from the transition period had to be excluded. Due to a higher flow rate of the sample air through the drift tube, the response time was strongly improved during CLOUD7 and CLOUD8.
A total of 36 different VOCs above their individual LOD could be detected. The most predominant compounds, which account for about $75 \%$ of the total VOCs, are listed in Table 1.

On average, $\mathrm{CH}_{2} \mathrm{OH}+$ (e.g. formaldehyde) and $\mathrm{CH}_{2} \mathrm{O}_{2} \mathrm{H}+$ (e.g. formic acid) account for $50 \%$ of total VOCs. Other important impurities are $\mathrm{C}_{2} \mathrm{H}_{4} \mathrm{O}_{2} \mathrm{H}+$ (e.g. acetic acid), $\mathrm{C}_{2} \mathrm{H}_{4} \mathrm{OH}+$ (e.g. acetaldehyde) and $\mathrm{C}_{3} \mathrm{H}_{6} \mathrm{OH}+$ (e.g. acetone/propanal). Those compounds have a rather high vapour pressure and are therefore not important for nucleation and growth (compare Kroll et al., 2005).

Although $\mathrm{CH}_{2} \mathrm{OH}+$ and $\mathrm{CH}_{2} \mathrm{O}_{2} \mathrm{H}+$ are treated as formaldehyde and formic acid in this work, an interference with fragments from methyl hydroperoxide and hydroxy methyl hydroperoxide, with considerably lower vapour pressure (Kroll and Seinfeld, 2008), cannot be ruled out.

Figure 4 shows a summary of measurements made at the start of several CLOUD campaigns, before intentional addition of any organic vapours. In panel e the sum of all detected VOCs is plotted. Panel $f$ shows the sum of the detected VOCs on a carbon basis. In parallel the gases ozone (panel d), $\mathrm{SO}_{2}$ (panel c) and the physical properties (temperature (panel b), and relative humidity (panel a)) that potentially impact the detected VOCs are shown.

The longest time series concerning the background contamination of the chamber is available for CLOUD3 (about 35 days). Instrumental problems shortened the time series for CLOUD2 to about 12 days. Only a short time series is available for CLOUD7 since DMA was added to the chamber early in the campaign. 
Table 1. Vapour pressure (from http://www.chemspider.com, Kroll and Seinfeld, 2005), individual abundance (CLOUD2 and CLOUD3), limit of detection (LOD), and sensitivity of the most predominant (about $75 \%$ of the total VOC volume mixing ratio) peaks detected by PTR-ToF during CLOUD3.

\begin{tabular}{|c|c|c|c|c|c|c|c|}
\hline $\begin{array}{r}\text { Exact } \\
\text { mass }\end{array}$ & Sum formula & compound (e.g.) & $\begin{array}{l}\text { Vapour pressure } \\
\left(\mathrm{mmHg} \text { at } 25^{\circ} \mathrm{C}\right)\end{array}$ & $\begin{array}{r}\text { CLOUD2 relative } \\
\text { abundance } \\
\text { min/mean/max }[\%]\end{array}$ & $\begin{array}{r}\text { CLOUD3 relative } \\
\text { abundance } \\
\text { min/mean/max [\%] }\end{array}$ & $\begin{array}{r}\text { LOD } \\
\text { [pptv] }\end{array}$ & $\begin{array}{l}\text { Sensitivity } \\
\text { [ncps/ppbv] }\end{array}$ \\
\hline 31.018 & $\mathrm{CH}_{2} \mathrm{OH}+$ & formaldehyde & $23-26$ & $25 / 36 / 59$ & $1.25 / 33 / 41$ & 97 & $1.6-3.25$ \\
\hline 45.034 & $\mathrm{C}_{2} \mathrm{H}_{4} \mathrm{OH}+$ & acetaldehyde & 965 & $6 / 10 / 16$ & $5.5 / 9 / 25$ & 17 & 18.6 \\
\hline 47.013 & $\mathrm{CH}_{2} \mathrm{O}_{2} \mathrm{H}+$ & formic acid & 41 & $0.1 / 14 / 23$ & $<\mathrm{LOD} / 21 / 41$ & 43 & 19.5 \\
\hline 59.049 & $\mathrm{C}_{3} \mathrm{H}_{6} \mathrm{OH}+$ & acetone/propanal & $348 / 300$ & $3 / 5 / 13$ & $2.5 / 5 / 31$ & 9 & 19.5 \\
\hline 61.029 & $\mathrm{C}_{2} \mathrm{H}_{4} \mathrm{O}_{2} \mathrm{H}+$ & acetic acid & 14 & $<\mathrm{LOD} / 8 / 9$ & $<\mathrm{LOD} / 14 / 45$ & 61 & 13 \\
\hline
\end{tabular}

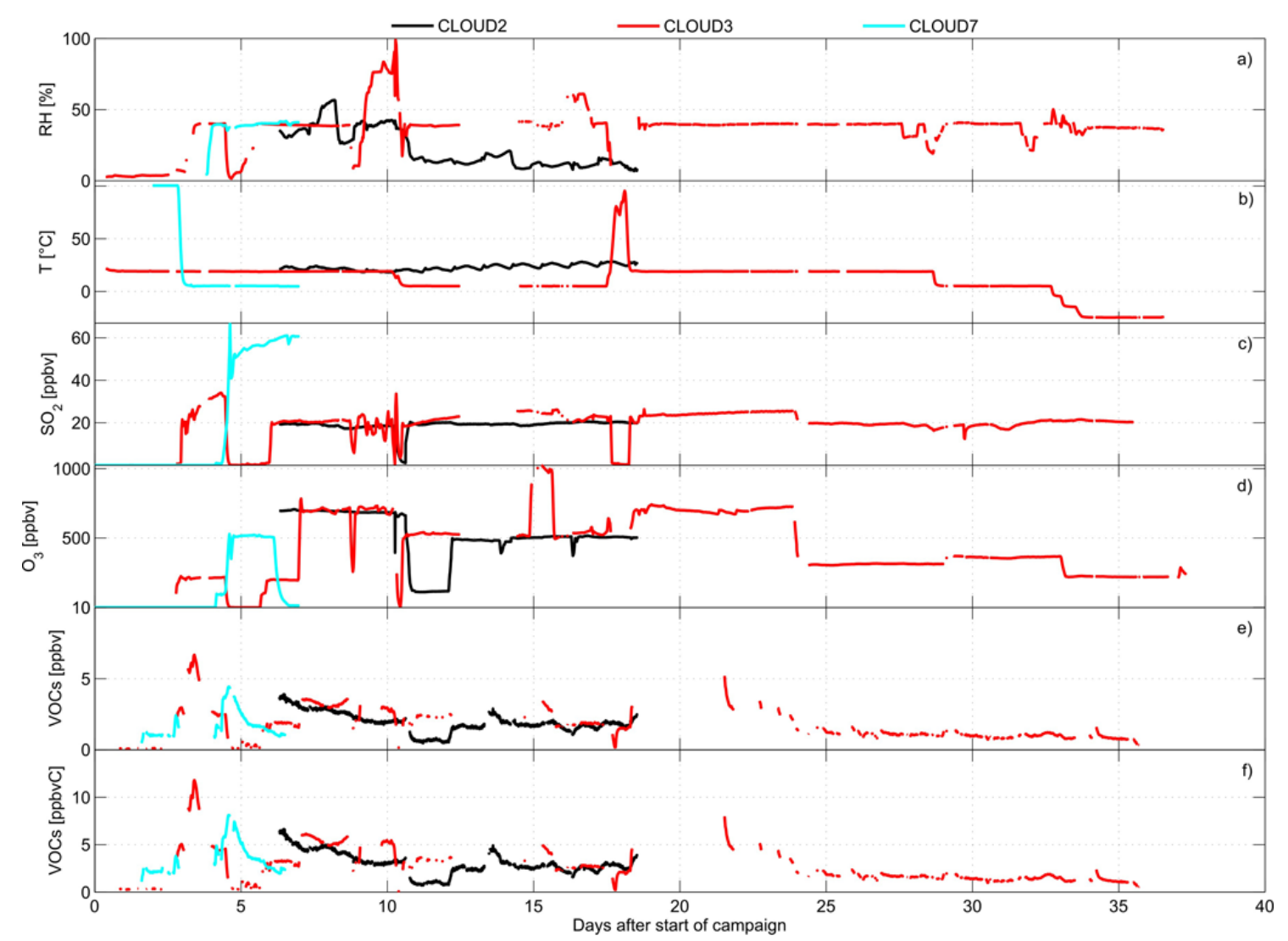

Figure 4. Temporal evolution of relative humidity (a), temperature (b), $\mathrm{SO}_{2}$ (c), ozone (d), total VOCs (e), and total VOCs on a carbon basis (f) during CLOUD2, CLOUD3, and CLOUD7.

Although the measured equilibrium organic contaminant levels are around a factor of 10 lower than the PSI teflon smog chamber which is of comparable size, the contamination was higher than expected and variable. At the beginning of the campaigns, a burst of VOCs (up to 7 ppbv total VOCs) was detected as soon as water vapour, ozone, or $\mathrm{SO}_{2}$ were added (CLOUD3 and CLOUD7 in Fig. 4). This is in agreement with Wisthaler et al. (2008), who report an increase of formaldehyde and other $\mathrm{C}_{2}-\mathrm{C}_{10}$ aldehydes during the first hour after ozone addition to the atmosphere simulation chamber SAPHIR (Jülich, Germany). After some hours the VOC concentration decays although the injected gases remain at a constant level. After this "chamber-startup burst", the VOC contamination tends to decrease. This indicates that impurities on the chamber walls and the inlet tubes of the gas supply system are gradually removed.

The most obvious source of the contamination is the gas injection system of the chamber. Nitrogen and oxygen are evaporated from cryogenic liquids and injected into the chamber at a constant rate of about $160 \mathrm{slpm}$. When only 


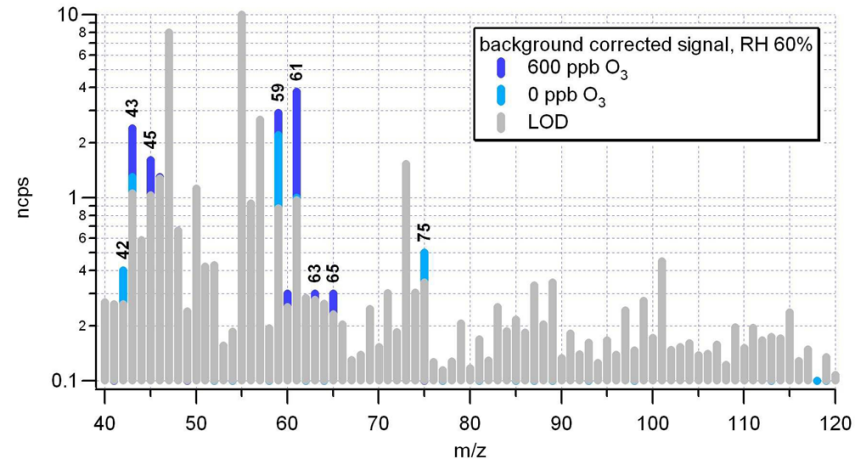

Figure 5. Comparison of mass spectra of the background VOC in the CLOUD chamber during CLOUD1. All spectra are averaged for $2 \mathrm{~h}$ and background-corrected. The grey bars at the bottom of individual mass fragments are the associated LOD.

these gases were added to the chamber, total VOCs were below 150 pptv (400 pptvC; compare Fig. 4).

In order to estimate possible contamination through the humidifying system, the purity of the water was checked using liquid chromatography. The total organic carbon (TOC) content was found to be $<7 \mathrm{ppbv}$, which could explain $<70 \mathrm{pptvC}$ in humid air at $20^{\circ} \mathrm{C}$ and $40 \% \mathrm{RH}$. However, organics may be subsequently introduced by the Nafion humidifier.

Another source might be adsorption, followed by desorption from the chamber wall depending on internal temperature. However, no significant influence on the VOC concentration was found during the heating cycles shown in Figs. 4 and 7. Instead, the desorption of organics seems to be triggered by water vapour (compare CLOUD3 in Fig. 4).

Figure 5 shows a full mass scan measured during CLOUD1 at 0 and at $600 \mathrm{ppbv} \mathrm{O}_{3}$. As before, only a few compounds are responsible for the overall VOC contamination. Most of the masses above the LOD increase when ozone is added to the chamber. Consequently, ozone was found to correlate with total VOCs, as shown in Fig. 6. An increase of $300 \mathrm{ppbv}$ ozone resulted in an increase of total VOCs by $1 \mathrm{ppbv}$, but less than 0.25 ppbv during CLOUD7 (data from the "chamber-startup bursts" have been excluded here), and even lower (0.05 ppbv) during CLOUD8. This can be attributed to the replacement of the ozone generator after CLOUD3 with an all-metal/quartz construction. On the other hand, the ozone effect could be an artefact caused by surfaceassisted reactions in the instruments inlets. To evaluate this, the inlet flow was varied at $600 \mathrm{ppbv}$ ozone between 0.4 and 2 slpm during CLOUD1, but no significant difference was found. The significant higher VOC level whith zero ozone during CLOUD7, compared to CLOUD3, 4, and 8 is due to the fact that during CLOUD7 the data for this plot were recorded in first days of chamber operation. Therefore contaminats adsorbed on the chamber walls were higher, since they are subsequently washed of during the campaigns (compare Fig. 6).

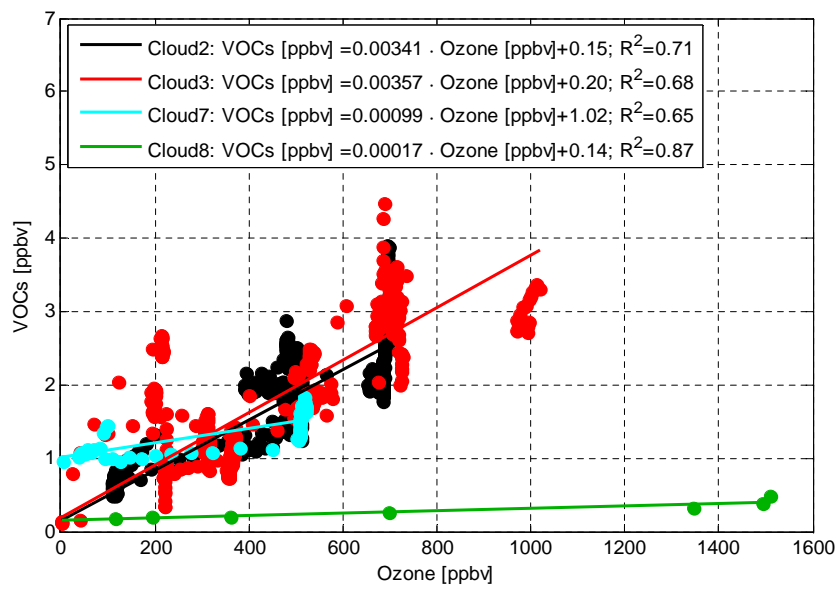

Figure 6. Scatter plot of ozone versus total VOCs for CLOUD2, CLOUD3, CLOUD7, and CLOUD8.

During the experiments $\mathrm{H}_{2} \mathrm{SO}_{4}$ was produced from photooxidation of $\mathrm{SO}_{2}$. The $\mathrm{OH}$ radical involved in this process, produced from ozone and $\mathrm{H}_{2} \mathrm{O}$ in the presence of UV, potentially produces oxygenated VOCs. However, no connection between UV intensity and total or individual background VOCs could be found.

To quantify the different contamination sources better, an experiment was conducted at the beginning of CLOUD7 (see Fig. 7). After the chamber was filled with the synthetic air, it was heated to $100{ }^{\circ} \mathrm{C}$ for 2 days. No significant difference in total VOCs appears between $100^{\circ} \mathrm{C}$ (30 September 2012) and $5{ }^{\circ} \mathrm{C}\left(2\right.$ October 2012 ) before $\mathrm{H}_{2} \mathrm{O}, \mathrm{SO}_{2}$ and ozone were added sequentially (Fig. 7b) Nevertheless the chamber cleanliness benefits from a heating cycle, after a specific VOC has been added to the chamber for experimental reasons. Total VOCs were constant at about 1000 pptv except in the afternoon of 30 Septemper when the signal increased to $2500 \mathrm{pptv}$ for a few hours. This can be related to the first introduction of ozone. Since many sensors (including the ozone analyser) have been disconnected from the chamber during the heating cycle, no measured data are available and the ozone concentration can only be estimated from the mass flow controller settings. The intention was to reach $200 \mathrm{ppbv}$ ozone from 30 September at 17:40 UTC on. At 20:30 UTC on the same day, ozone was set to zero again. Due to the thermal contraction of the chamber during cooling to $5^{\circ} \mathrm{C}$, the inflexible PTR-ToF inlet developed a leak, resulting in loss of data for 1 day. After recovery of the PTR-ToF, gases were sequentially added to the chamber. Injection of $100 \mathrm{ppbv}$ ozone produced a step increase of total VOCs from 1000 to 1900 pptv. After $4 \mathrm{~h}$, the total VOCs declined to $1400 \mathrm{pptv}$. On 2 October at 09:00 UTC, $\mathrm{SO}_{2}$ was added to chamber and increased over the next $10 \mathrm{~h}$ to a constant level around $50 \mathrm{ppbv}$. In contrast to the slowly increasing $\mathrm{SO}_{2}$ signal, total VOCs increased to 3500 pptv within 15 min of first opening the $\mathrm{SO} 2$ inlet valve. This is interpreted as contamination in the $\mathrm{SO}_{2}$ 


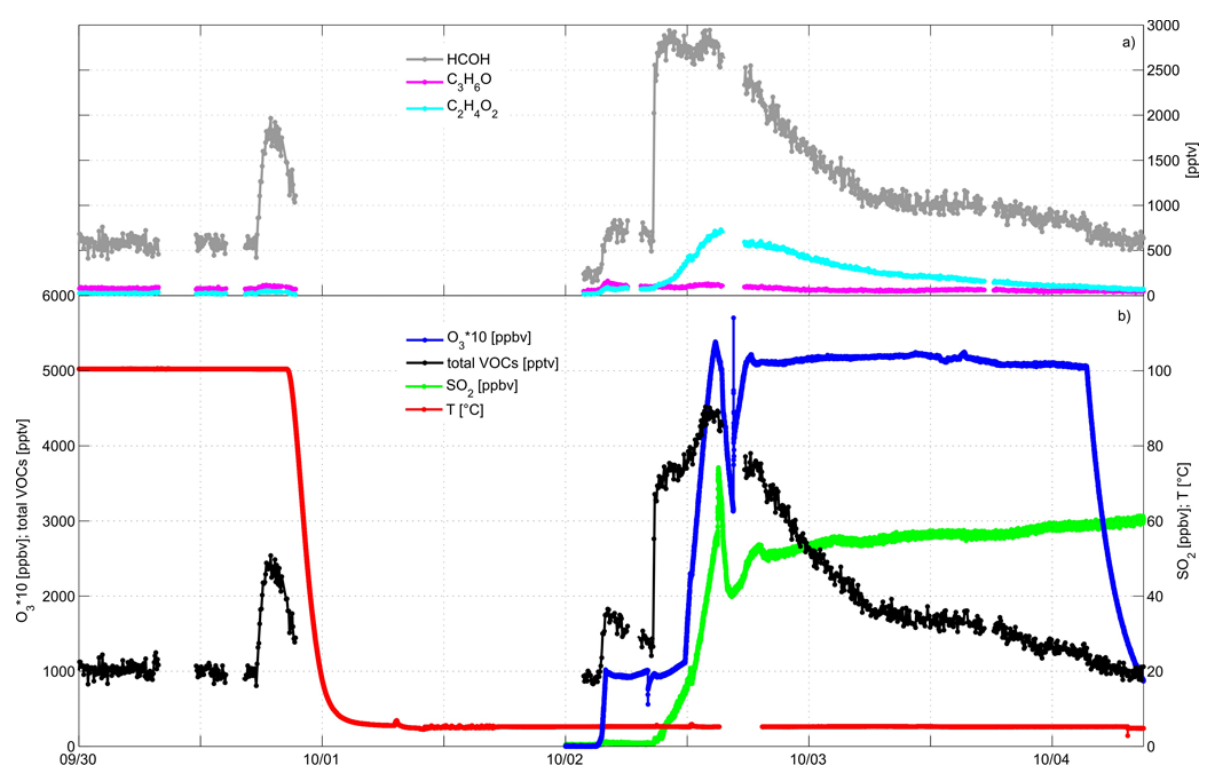

Figure 7. Total (b) and individual VOCs (a) at the beginning of CLOUD7, when following a heating cycle, ozone and $\mathrm{SO}_{2}$ were sequentially added to the chamber.

inlet line, which was flushed for the first time in several months during this event. About $90 \%$ of this increase can be attributed to formaldehyde (see Fig. 7b). In the next step ozone was increased from $100 \mathrm{ppbv}$ (11:45 UTC, 2 October) to $500 \mathrm{ppbv}$ (15:00 UTC). The corresponding VOC increase was rather slow and followed the ozone concentration. The most abundant individual compound during this event was acetic acid (Fig. 7b). No VOC information is available during the short dip (2 h) seen in ozone and $\mathrm{SO}_{2}$ since the PTR-ToF background was being measured at that time. Until 4 October at 03:00 UTC (i.e. $18 \mathrm{~h}$ ), the ozone and $\mathrm{SO}_{2}$ were constant around $515 \mathrm{ppbv}$, and $55 \mathrm{ppbv}$, respectively. Total VOCs reached their maximum level of 4500 pptv on 2 October at 15:00 UTC, when ozone and $\mathrm{SO}_{2}$ obtained their set points. However, the total VOC peak lasted only a few hours and the signal slowly declined, reaching 1000 pptv by 4 October. Afterwards ozone was set to $15 \mathrm{ppbv}$ and nucleation experiments started.

Data from this experiment show that flushing the whole gas inlet system and a water vapour/ozone cleaning cycle washes off a large amount of organic contaminants from metal surfaces, and reduces their equilibrium concentrations during the subsequent nucleation experiments. During the CLOUD8 campaign (October 2013), a special effort was made to reach the cleanest possible conditions in the chamber. This included an extended ( $24 \mathrm{~h}$ ) rinsing of the chamber walls with ultra-pure water, followed by heating the chamber to $100^{\circ} \mathrm{C}$ for a further $24 \mathrm{~h}$ while flushing at high rate (approx. $400 \mathrm{~L} \mathrm{~min}^{-1}$ ) with humidified synthetic air and elevated ozone (few ppmv). This resulted in extremely low contaminant vapour concentrations; the total organics contamination (comprising high volatility C1-C3 compounds) was below 400 pptv at 1500 ppbv ozone and below 200 pptv at $100 \mathrm{ppbv}$ ozone ( $38 \%$ relative humidity and $278 \mathrm{~K})$.

\section{Conclusions}

Total organic impurities in the CLOUD chamber were found between 0.1 and $7 \mathrm{ppbv}$, and 0.4 and $12 \mathrm{ppbvC}$, respectively. The organic impurities are dominated by light $\mathrm{C}_{1}-\mathrm{C}_{3}$ organics of high vapour pressure, which are not important for particle nucleation and growth. A correlation between ozone and total background VOCs was found. After replacing all plastic parts of the ozone generator with stainless steel and quartz, the ozone effect decreased by more than a factor of 4 . After CLOUD3, the ozone concentration for the nucleation experiments was always below 100 ppbv. During these ozone levels, the total VOC contamination was usually below 1 ppbv. Therefore, the CLOUD chamber was found to be considerably cleaner than a comparable Teflon chamber. Beside the ozone-generator effect, ozone yields to VOC formation by heterogeneous reactions on the chamber walls. In addition, water vapour appears to release organic compounds from the chamber walls, especially when introduced for the first time after completely dry conditions. A significant contamination source - but of short time duration - is the dead volume of the various trace gas tubes connected to the chamber; this can be avoided by carefully flushing before starting the experiments, as done during CLOUD8. A comprehensive cleaning cycle includes an extended $(24 \mathrm{~h})$ rinsing of the chamber walls with ultra-pure water, followed by heating the chamber to $373 \mathrm{~K}$ for a further $24 \mathrm{~h}$ while flushing at high rate (approx. $400 \mathrm{~L} \mathrm{~min}^{-1}$ ) with humidified synthetic air and elevated ozone (few ppmv). 
Acknowledgements. We would like to thank CERN for supporting CLOUD with important technical and financial resources, and for providing a particle beam from the CERN Proton Synchrotron. This research has received funding from the EC Seventh Framework Programme (Marie Curie Initial Training Network "CLOUD-ITN" no. 215072, MC-ITN "CLOUD-TRAIN" no. 316662, and ERCAdvanced "ATMNUCLE" grant no. 227463), the German Federal Ministry of Education and Research (project nos. 01LK0902A and 01LK1222A), the Swiss National Science Foundation (project nos. 200020_135307 and 206620_130527), the Academy of Finland (Center of Excellence project no. 1118615), the Academy of Finland (135054, 133872, 251427, 139656, 139995, 137749, 141217, 141451), the Finnish Funding Agency for Technology and Innovation, the Nessling Foundation, the Austrian Science Fund (FWF; project no. P19546 and L593), the Portuguese Foundation for Science and Technology (project no. CERN/FP/116387/2010), the Swedish Research Council, Vetenskapsradet (grant 2011-5120), the Presidium of the Russian Academy of Sciences and Russian Foundation for Basic Research (grants 08-02-91006-CERN and 12-02-91522-CERN), and the US National Science Foundation (grants AGS1136479 and CHE1012293).

Edited by: J. Abbatt

\section{References}

Almeida, J., Schobesberger, S., Kuerten, A., Ortega, I. K., Kupiainen, O., Praplan, A. P., Adamov, A., Amorim, A., Bianchi, F., Breitenlechner, M., David, A., Dommen, J., Donahue, N. M., Downard, A., Dunne, E., Duplissy, J., Ehrhart, S., Flagan, R. C., Franchin, A., Guida, R., Hakala, J., Hansel, A., Heinritzi, M., Henschel, H., Jokinen, T., Junninen, H., Kajos, M., Kangasluoma, J., Keskinen, H., Kupc, A., Kurten, T., Kvashin, A. N., Laaksonen, A., Lehtipalo, K., Leiminger, M., Leppae, J., Loukonen, V., Makhmutov, V., Mathot, S., McGrath, M. J., Nieminen, T., Olenius, T., Onnela, A., Petaejae, T., Riccobono, F., Riipinen, I., Rissanen, M., Rondo, L., Ruuskanen, T., Santos, F. D., Sarnela, N., Schallhart, S., Schnitzhofer, R., Seinfeld, J. H., Simon, M., Sipilae, M., Stozhkov, Y., Stratmann, F., Tome, A., Troestl, J., Tsagkogeorgas, G., Vaattovaara, P., Viisanen, Y., Virtanen, A., Vrtala, A., Wagner, P. E., Weingartner, E., Wex, H., Williamson, C., Wimmer, D., Ye, P., Yli-Juuti, T., Carslaw, K. S., Kulmala, M., Curtius, J., Baltensperger, U., Worsnop, D. R., Vehkamaeki, H., and Kirkby, J.: Molecular understanding of amine-sulphuric acid particle nucleation in the atmosphere, Nature, 502, 359-363, doi:10.1038/nature12663, 2013.

Bianchi, F., Dommen, J., Mathot, S., and Baltensperger, U.: Online determination of ammonia at low pptv mixing ratios in the CLOUD chamber, Atmos. Meas. Tech., 5, 1719-1725, doi:10.5194/amt-5-1719-2012, 2012.

Bloss, C., Wagner, V., Bonzanini, A., Jenkin, M. E., Wirtz, K., Martin-Reviejo, M., and Pilling, M. J.: Evaluation of detailed aromatic mechanisms (MCMv3 and MCMv3.1) against environmental chamber data, Atmos. Chem. Phys., 5, 623-639, doi:10.5194/acp-5-623-2005, 2005.

Cappellin, L., Karl, T., Probst, M., Ismailova, O., Winkler, P. M., Soukoulis, C., Aprea, E., Maerk, T. D., Gasperi, F., and Biasioli, F.: On Quantitative Determination of Volatile Organic Compound Concentrations Using Proton Transfer Reaction Time-of-
Flight Mass Spectrometry, Environ. Sci. Technol., 46, 2283 2290, doi:10.1021/es203985t, 2012.

Carslaw, K., Harrison, R., and Kirkby, J.: Cosmic rays, clouds, and climate, Science, 298, 1732-1737, doi:10.1126/science.1076964, 2002.

Cocker, D., Flagan, R., and Seinfeld, J.: State-of-the-art chamber facility for studying atmospheric aerosol chemistry, Environ. Sci. Technol., 35, 2594-2601, doi:10.1021/es0019169, 2001.

de Gouw, J., Warneke, C., Karl, T., Eerdekens, G., van der Veen, C., and Fall, R.: Sensitivity and specificity of atmospheric trace gas detection by proton-transfer-reaction mass spectrometry, Int. J. Mass Spectrom., 223, 365-382, 2003.

Duplissy, J., Enghoff, M. B., Aplin, K. L., Arnold, F., Aufmhoff, H., Avngaard, M., Baltensperger, U., Bondo, T., Bingham, R., Carslaw, K., Curtius, J., David, A., Fastrup, B., Gagné, S., Hahn, F., Harrison, R. G., Kellett, B., Kirkby, J., Kulmala, M., Laakso, L., Laaksonen, A., Lillestol, E., Lockwood, M., Mäkelä, J., Makhmutov, V., Marsh, N. D., Nieminen, T., Onnela, A., Pedersen, E., Pedersen, J. O. P., Polny, J., Reichl, U., Seinfeld, J. H., Sipilä, M., Stozhkov, Y., Stratmann, F., Svensmark, H., Svensmark, J., Veenhof, R., Verheggen, B., Viisanen, Y., Wagner, P. E., Wehrle, G., Weingartner, E., Wex, H., Wilhelmsson, M., and Winkler, P. M.: Results from the CERN pilot CLOUD experiment, Atmos. Chem. Phys., 10, 1635-1647, doi:10.5194/acp-101635-2010, 2010.

Graus, M., Mueller, M., and Hansel, A.: High Resolution PTR-TOF: Quantification and Formula Confirmation of VOC in Real Time, J. Am. Soc. Mass Spectr., 21, 1037-1044, doi:10.1016/j.jasms.2010.02.006, 2010.

Hansel, A., Jordan, A., Holzinger, R., Prazeller, P., Vogel, W., and Lindinger, W.: Proton transfer reaction mass spectrometry: online trace gas analysis at the ppb level, Int. J. Mass. Spectrom., 149, 609-619, 1995.

Hansel, A., Singer, W., Wisthaler, A., Schwarzmann, M., and Lindinger, W.: Energy dependencies of the proton transfer reactions $\mathrm{H}_{3} \mathrm{O}(+)+\mathrm{CH}_{2} \mathrm{O}$ double left right arrow $\mathrm{CH}_{2} \mathrm{OH}^{+}+\mathrm{H}_{2} \mathrm{O}$, Int. J. Mass Spectrom., 167, 697-703, doi:10.1016/S01681176(97)00128-6, 1997.

Keskinen, H., Virtanen, A., Joutsensaari, J., Tsagkogeorgas, G., Duplissy, J., Schobesberger, S., Gysel, M., Riccobono, F., Slowik, J G., Bianchi, F., Yli-Juuti, T., Lehtipalo, K., Rondo, L., Breitenlechner, M., Kupc, A., Almeida, J., Amorim, A., Dunne, E. M., Downard, A. J., Ehrhart, S., Franchin, A., Kajos, M. K., Kirkby, J., Kürten, A., Nieminen, T., Makhmutov, V., Mathot, S., Miettinen, P., Onnela, A., Petäjä, T., Praplan, A., Santos, F. D., Schallhart, S., Sipilä, M., Stozhkov, Y., Tomé, A., Vaattovaara, P., Wimmer, D., Prevot, A., Dommen, J., Donahue, N. M., Flagan, R.C., Weingartner, E., Viisanen, Y., Riipinen, I., Hansel, A., Curtius, J., Kulmala, M., Worsnop, D. R., Baltensperger, U., Wex, H., Stratmann, F., and Laaksonen, A.: Evolution of particle composition in CLOUD nucleation experiments, Atmos. Chem. Phys., 13, 5587-5600, doi:10.5194/acp-13-5587-2013, 2013.

Kirkby, J., Curtius, J., Almeida, J., Dunne, E., Duplissy, J., Ehrhart, S., Franchin, A., Gagne, S., Ickes, L., Kuerten, A., Kupc, A., Metzger, A., Riccobono, F., Rondo, L., Schobesberger, S., Tsagkogeorgas, G., Wimmer, D., Amorim, A., Bianchi, F., Breitenlechner, M., David, A., Dommen, J., Downard, A., Ehn, M., Flagan, R. C., Haider, S., Hansel, A., Hauser, D., Jud, W., Junninen, H., Kreissl, F., Kvashin, A., Laaksonen, A., Lehtipalo, K., 
Lima, J., Lovejoy, E. R., Makhmutov, V., Mathot, S., Mikkila, J., Minginette, P., Mogo, S., Nieminen, T., Onnela, A., Pereira, P., Petaja, T., Schnitzhofer, R., Seinfeld, J. H., Sipila, M., Stozhkov, Y., Stratmann, F., Tome, A., Vanhanen, J., Viisanen, Y., Vrtala, A., Wagner, P. E., Walther, H., Weingartner, E., Wex, H., Winkler, P. M., Carslaw, K. S., Worsnop, D. R., Baltensperger, U., and Kulmala, M.: Role of sulphuric acid, ammonia and galactic cosmic rays in atmospheric aerosol nucleation, NATURE, 476, 429-477, doi:10.1038/nature10343, 2011.

Kroll, J. and Seinfeld, J.: Representation of secondary organic aerosol laboratory chamber data for the interpretation of mechanisms of particle growth, Environ. Sci. Technol., 39, 4159-4165, doi:10.1021/es048292h, 2005.

Kroll, J. H. and Seinfeld, J. H.: Chemistry of secondary organic aerosol: Formation and evolution of low-volatility organics in the atmosphere, Atmos. Environ., 42, 3593-3624, doi:10.1016/j.atmosenv.2008.01.003g, 2008.

Kroll, J., Ng, N., Murphy, S., Varutbangkul, V., Flagan, R., and Seinfeld, J.: Chamber studies of secondary organic aerosol growth by reactive uptake of simple carbonyl compounds, J. of Geophys. Res.-Atmos., 110, doi:10.1029/2005JD006004, 2005.

Kulmala, M., Kontkanen, J., Junninen, H., Lehtipalo, K., Manninen, H. E., Nieminen, T., Petaja, T., Sipila, M., Schobesberger, S., Rantala, P., Franchin, A., Jokinen, T., Jarvinen, E., Aijala, M., Kangasluoma, J., Hakala, J., Aalto, P. P., Paasonen, P., Mikkila, J., Vanhanen, J., Aalto, J., Hakola, H., Makkonen, U., Ruuskanen, T., Mauldin, III, R. L., Duplissy, J., Vehkamaki, H., Back, J., Kortelainen, A., Riipinen, I., Kurten, T., Johnston, M. V., Smith, J. N., Ehn, M., Mentel, T. F., Lehtinen, K. E. J., Laaksonen, A., Kerminen, V.-M., and Worsnop, D. R.: Direct Observations of Atmospheric Aerosol Nucleation, Science, 339, $943-$ 946, doi:10.1126/science.1227385, 2013.

Kupc, A., Amorim, A., Curtius, J., Danielczok, A., Duplissy, J., Ehrhart, S., Walther, H., Ickes, L., Kirkby, J., Kuerten, A., Lima, J. M., Mathot, S., Minginette, P., Onnela, A., Rondo, L., and Wagner, P. E.: A fibre-optic UV system for $\mathrm{H}_{2} \mathrm{SO}_{4}$ production in aerosol chambers causing minimal thermal effects, J. Aerosol Sci., 42, 532-543, doi:10.1016/j.jaerosci.2011.05.001, 2011.

Metzger, A., Verheggen, B., Dommen, J., Duplissy, J., Prevot, A. S. H., Weingartner, E., Riipinen, I., Kulmala, M., Spracklen, D. V., Carslaw, K. S., and Baltensperger, U.: Evidence for the role of organics in aerosol particle formation under atmospheric conditions, Proc. Natl. Aca. Sci. USA, 107, 6646-6651, doi:10.1073/pnas.0911330107, 2010.

Müller, M., Graus, M., Wisthaler, A., Hansel, A., Metzger, A., Dommen, J., and Baltensperger, U.: Analysis of high mass resolution PTR-TOF mass spectra from 1,3,5-trimethylbenzene (TMB) environmental chamber experiments, Atmos. Chem. Phys., 12, 829-843, doi:10.5194/acp-12-829-2012, 2012.
Paulsen, D., Dommen, J., Kalberer, M., Prevot, A., Richter, R., Sax, M., Steinbacher, M., Weingartner, E., and Baltensperger, U.: Secondary organic aerosol formation by irradiation of 1,3,5trimethylbenzene- $\mathrm{NO}_{x}-\mathrm{H}_{2} \mathrm{O}$ in a new reaction chamber for atmospheric chemistry and physics, Environ. Sci. Technol., 39, 2668-2678, doi:10.1021/es0489137, 2005.

Praplan, A. P., Bianchi, F., Dommen, J., and Baltensperger, U.: Dimethylamine and ammonia measurements with ion chromatography during the CLOUD4 campaign, Atmos. Meas. Tech., 5, 2161-2167, doi:10.5194/amt-5-2161-2012, 2012.

Schobesberger, S., Junninen, H., Bianchi, F., Lönn, G., Ehn, M., Lehtipalo, K., Dommen, J., Ehrhart, S., Ortega, I. K., Franchin, A., Nieminen, T., Riccobono, F., Hutterli, M., Duplissy, J., Almeida, J., Amorim, A., Breitenlechner, M., Downard, A. J., Dunne, E. M., Flagan, R. C., Kajos, M., Keskinen, H., Kirkby, J., Kupc, A., Kürten, A., Kurtén, T., Laaksonen, A., Mathot, S., Onnela, A., Praplan, A. P., Rondo, L., Santos, F. D., Schallhart, S., Schnitzhofer, R., Sipilä, M., Tomé, A., Tsagkogeorgas, G., Vehkamäki, H., Wimmer, D., Baltensperger, U., Carslaw, K. S., Curtius, J., Hansel, A., Petäjä, T., Kulmala, M., Donahue, N. M., and Worsnop, D. R.: Molecular understanding of atmospheric particle formation from sulfuric acid and large oxidized organic molecules, Proc. Natl. Aca. Sci., 110, 17223-17228, doi:10.1073/pnas.1306973110, 2013.

Solomon, S., Qin, D., Manning, M., Chen, Z., Marquis, M., Averyt, K., Tignor, M., and Miller, H. E.: IPCC, 2007: Summary for Policymakers, in: Climate Change 2007: The Physical Science Basis. Contribution of Working Group I to the Fourth Assessment Report of the Intergovernmental Panel on Climate Change, Cambridge University Press, 2007.

Vlasenko, A., Macdonald, A .M., Sjostedt, S. J., and Abbatt, J. P. D.: Formaldehyde measurements by Proton transfer reaction - Mass Spectrometry (PTR-MS): correction for humidity effects, Atmos. Meas. Tech., 3, 1055-1062, doi:10.5194/amt-3-1055-2010, 2010.

Voigtländer, J., Duplissy, J., Rondo, L., Kürten, A., and Stratmann, F.: Numerical simulations of mixing conditions and aerosol dynamics in the CERN CLOUD chamber, Atmos. Chem. Phys., 12, 2205-2214, doi:10.5194/acp-12-2205-2012, 2012.

Warneke, C., Veres, P., Holloway, J. S., Stutz, J., Tsai, C., Alvarez, S., Rappenglueck, B., Fehsenfeld, F. C., Graus, M., Gilman, J. B., and de Gouw, J. A.: Airborne formaldehyde measurements using PTR-MS: calibration, humidity dependence, intercomparison and initial results, Atmos. Meas. Tech., 4, 23452358, doi:10.5194/amt-4-2345-2011, 2011.

Wisthaler, A., Apel, E. C., Bossmeyer, J., Hansel, A., Junkermann, W., Koppmann, R., Meier, R., Müller, K., Solomon, S. J., Steinbrecher, R., Tillmann, R., and Brauers, T.: Technical Note: Intercomparison of formaldehyde measurements at the atmosphere simulation chamber SAPHIR, Atmos. Chem. Phys., 8, 21892200, doi:10.5194/acp-8-2189-2008, 2008. 